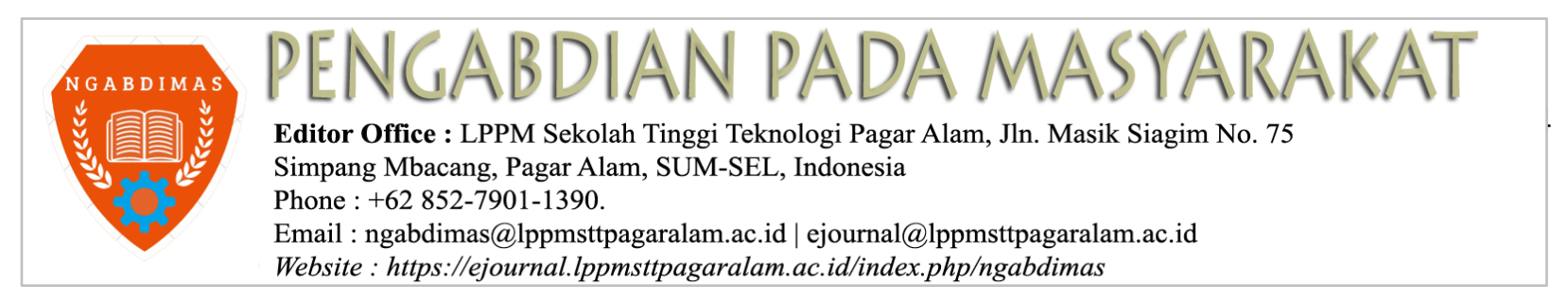

\title{
Workshop Multimedia Pembelajaran Bagi Guru SMPN 8 Kota Pagar Alam
}

\author{
Risnaini Masdalipa ${ }^{1}$, Debi Gusmaliza ${ }^{2}$ \\ Program Studi Teknik Informatika; Sekolah Tinggi Teknologi Pagaralam (STTP) \\ Jl. M. Siagim No.75 Kel. Karang Dalo, Dempo Tengah, Kota Pagar Alam \\ Telp/Fax: (0730) 621916
}

e-mail: risnainipga@gmail.com¹.debigusmaliza13@gmail.com² ${ }^{2}$.

\begin{abstract}
Abstrak
Pembelajaran merupakan sarana untuk mengembangkan intelektualitas generasi muda, khususnya generasi muda Pagar Alam. SMPN 8 Kota Pagaralam merupakan pendidikan menengah pertama yang mempersiapkan soft dan hardskills bagi generasi pemimpin mendatang, penyampaian pembelajaran yang baik sangat menentukan keberhasilan dan kualitas output (alumni) yang sangat diharapkan, menyadari hal ini maka pihak SMPN 8 terus berupaya melatih para guru agar dapat menyampaikan materi belajar dengan baik, sarana terus dilengkapi, workshop multimedia pembelajaran merupakan satu upaya SMPN 8 dalam meningkatkan mutu pembelajaran dengan menggunakan aplikasi tambahan berupa multimedia, workshop dilakukan satu hari dengan metode ceramah dan praktek dengan aplikasi multimedia pembelajaran, yang mana agar pelaksanaan pelatihan berjalan dengan baik maka dilakukan pre tes terlebih dahulu hasilnya sebagian guru sudah memahami beberapa aplikasi multimedia yang digunakan untuk pembelajaran tetapi tidak memanfaatkannya sehingga yang baru paham akhirnya menjadi tidak bisa lagi, pada akhir workshop dilakukan pos tes hasilnya seluruh peserta workshop memahami materi dengan baik, bahkan yang tadinya males menggunakan multimedia setelah diadakan workshop malah jadi lebih tertarik untuk mengaplikasikannya pada pembelajaran.
\end{abstract}

Kata kunci-Pembelajaran, Pagaralam, SMP, Multimedia, Workshop, Aplikasi.

\section{PENDAHULUAN.}

Pada saat ini perkembangan teknologi informasi dan komunikasi (TIK) terutama untuk pendukung kegiatan kehidupan, teknologi khususnya teknologi informasi saat ini sangat mempengaruhi gaya hidup manusia, salah satunya adalah penggunaan sistem komputer yang merupakan salah satu fasilitas dari penujang hidup. Media ini sangat banyak sekali digunakan di setiap bidang dan profesi.Termasuk dalam hal ini adalah penggunaan aplikasi yang mendukung teknologi komputer yang berbasis multimedia, perkembangan teknologi menjadikan multimedia pun mengikuti perkembangan sesuai perkembangan perangkat lunak yang umum di aplikasikan oleh pemakai komputer. Sebagai penunjang pada pelatihan ini komputer akan di aplikasikan sebagai multimedia untuk mendukung pembelajaran.

Multimedia pembelajaran yang mendukung terlaksananya sistem pembelajaran yang baik, dengan multimedia ini pembelajaran diharapkan lebih mengena dan lebih interaktif sehingga materi lebih di pahami secara mendalam oleh siswa, sehingga tujuan pembelajaran yang di inginkan SMP NEGERI 8 Pagar Alam benar-benar tercapai, dengan multimedia juga di katakana oleh para ahli materi makin mudah di pahami juga pembelajaran dan tentunya menjadi sangat menyenangkan, siswa dan siswi menjadi tambah bersemangat, karena sesuai dengan karakter usia sekolah menengah lebih senang dengan gambar dan karakter tertentu.

Dari pemaparan diatas tentu agar para Guru SMPN 8 Kota Pagar Alam lebih memahami dalam pemilihan media pembelajaran dengan sistem multimedia yang baik, tetapi sehingga pembelajaran dapat benar-benar maksimal, sehingga tercipta tenaga kerja yang benar-benar handal dan professional, sehingga pada pengabdian ini diambil tema yang sesuai yaitu: Workshop multimedia pembelajaran bagi Guru SMPN 8 Kota Pagar Alam. 


\section{METODE.}

Metodologi pelaksananaan yang digunakan pada kegiatan Pengabdian kepada masyarakat (PkM) ini adalah dengan menyimak (menonton) bersama, membaca bersama (modul pelatihan), memahami tools aplikasi (Software) dan berinteraksi secara langsung (Aplikatif) dengan software.

\subsection{Pengabdian Pada Masyarakat (PkM).}

Pengabdian masyarakat $(\mathrm{PkM})$ suatu kegiatan yang bertujuan membantu masyarakat tertentu pada beberapa aktivitas tanpa mengharapkan imbalan berbentuk apapun. Secara umum program ini dirancang institusi perguruan tinggi yang ada di Indonesia untuk memberikan kontribusi nyata bagi bangsa, khususnya pada pengembangan kesejahteraan dan kemajuan bangsa Indonesia. Kegiatan Pengabdian Masyarakat (PkM) merupakan salah satu bagian dari Tri Dharma Perguruan Tinggi (PkM). Bentuk-bentuk kegiatan Pengabdian Masyarakat: Bakti Sosial dan Mengajar. Tujuan Pengabdian Masyarakat di Perguruan Tinggi (PT), antara lain:

1. Meningkatkan upaya inovasi teknologi untuk mendorong pembangunan ekonomi dengan melakukan komersialisasi hasil penelitian;

2. Memberikan solusi berdasarkan kajian akademik atas kebutuhan, tantangan, atau persoalan yang dihadapi masyarakat, baik secara langsung maupun tidak langsung;

3. Melakukan kegiatan yang mampu mengentaskan masyarakat tersisih (preferential option for the poor) pada semua strata, yaitu masyarakat yang tersisih secara ekonomi, politik, sosial, dan budaya;

4. Melakukan alih teknologi, ilmu, dan seni kepada masyarakat untuk pengembangan martabat manusia dan kelestarian sumber daya alam.

\subsection{Multimedia.}

Multimedia itu penggunaan komputer untuk menyajikan dan menggabungkan teks, suara, gambar, animasi, audio dan video dengan alat bantu (tool) dan koneksi (link) sehingga pengguna mampu melakukan navigasi, berinteraksi, berkarya dan berkomunikasi. Multimedia sering digunakan di dunia informatika. Selain dunia informatika, multimedia juga diadopsi dunia game, dan juga untuk membuat website.

Multimedia berasal dari kata 'multi' dan 'media'. Multi berarti banyak, dan media berarti tempat, sarana atau alat yang digunakan untuk menyampaikan informasi. Jadi berdasarkan kata 'multimedia' dapat dirumuskan sedagai wadah atau penyatuan beberapa media yang kemudian didefinisikan sebagai elemen pembentukan multimedia. Elemen tersebut seperti teks, gambar, suara, animasi, dan video. Multimedia merupakan suatu konsep dan teknologi baru bidang teknologi informasi, di mana informasi dalam bentuk teks, gambar, suara, animasi, dan video disatukan komputer untuk disimpan, diproses dan disajikan baik secara liner mau pun interaktif. sehingga, dengan menggabungkan seluruh elemen multimedia tersebut menjadikan informasi dalam bentuk multimedia yang dapat diterima indera penglihatan dan pendengaran, lebih mendekati bentuk asli dalam dunia sebenarnya. Multimedia interaktif adalah apabila suatu aplikasi terdapat seluruh elemen multimedia yang ada dan pemakai (user) diberi keputusan atau kemampuan untuk mengawal dan menghidupkan elemen tersebut. Pengertian multimedia menurut beberapa Ahli:

a. Menurut McCormick (1996), Multimedia adalah kombinasi tiga elemen, suara, gambar, dan

b. Menurut Rosch (1996), Multimedia sebagai kombinasi dari komputer dan video.

c. Menurut Gumelar (2014), Multimedia adalah penggunaan komputer untuk menyajikan dan menggabungkan teks, animasi, suara, gambar dan video dengan tools dan link sehingga pengguna dapat melakukan navigasi, interaksi, berkarya dan berkomunikasi.

Multimedia dimanfaatkan juga pada dunia pendidikan dan bisnis. Di dunia pendidikan, multimedia digunakan sebagai media pengajaran, baik dalam kelas maupun secara sendiri-sendiri atau otodidak. Di dunia bisnis, multimedia digunakan sebagai media profil perusahaan, profil produk, bahkan sebagai media kios informasi dan pelatihan dalam sistem e-learning. Pada awalnya multimedia hanya mencakup media yang menjadi konsumsi indra penglihatan (gambar diam, teks, gambar gerak video, dan gambar gerak rekaan/animasi), dan konsumsi indra pendengaran (suara) dan juga berupa (berwujud). Dalam perkembangannya multimedia mencakup juga kinetik (gerak) dan bau yang merupakan konsumsi indra penciuman. Multimedia mulai memasukkan unsur kinetik 
sejak diaplikasikan pada pertunjukan film 3 dimensi yang digabungkan dengan gerakan pada kursi tempat duduk penonton. Kinetik, dan film 3 dimensi membangkitkan sense realistis.

Bau mulai menjadi bagian dari multimedia sejak ditemukan teknologi reproduksi bau melalui telekomunikasi. Dengan perangkat input pendeteksi bau, seorang operator dapat mengirimkan hasil digitizing bau tersebut melalui internet. Komputer penerima harus menyediakan perangkat output berupa mesin reproduksi bau. Mesin reproduksi bau ini mencampurkan berbagai jenis bahan bau yang setelah dicampur menghasilkan output berupa bau yang mirip dengan data yang dikirim dari internet. Dengan menganalogikan dengan printer, alat ini menjadikan feromonferomon bau sebagai pengganti tinta. Output bukan berupa cetakan melainkan aroma.

\subsection{Teknologi Informasi.}

Secara bahasa kata Teknologi Informasi (TI) berasal dari kata Information Technology. Kata Technology berdasarkan Kamus Advanced Leaner's Dictionary of Current English (1974) merupakan penerapan pengetahuan secara sistematis pada tugas praktis dalam suatu industri. Senada dengan definisi, Sulistyo-Basuki (1992:81) menyatakan bahwa Teknologi bisa diartikan sebagai pelaksanaan ilmu, sinonim dengan ilmu terapan.

Kata Informasi pada Oxford Advanced Learners's Dictionary of Current English (1980: 437), diartikan sebagai sesuatu yang diberitahukan, pengetahuan, dan berita. Sedang dalam Ilmu Informasi, kata "Informasi", "pengetahuan", dan "berita" dibedakan. Menurut Teskey (dalam Pendit,1992) data adalah hasil observasi langsung terhadap suatu kejadian, merupakan perlambangan yang mewakili objek atau konsep pada dunia nyata, dilengkapi dengan nilai tertentu; Informasi adalah kumpulan data terstruktur, disampaikan seseorang kepada orang lain. Sedangkan berita menurut Arifin (1997), adalah informasi menarik, penting dan belum pernah didengar. Informasi merupakan sarana baku untuk menunjang dan meningkatkan kegiatan bidang Ilmu Pengetahuan, kebudayaan, dan teknologi. Pengetahuan, adalah sesuatu digunakan manusia untuk memahami dunia, yang dapat diubah berdasarkan informasi yang diterima. Dalam makalah ini informasi secara singkat diartikan sebagai segala data, fakta, dan pengetahuan yang disampaikan kepada orang lain melalui berbagai media, dalam bentuk tekstual, gambar, maupun suara.

Teknologi informasi (TI) merupakan sebuah istilah baru yang merupakan terjemahan dari Information Technology Bagi kebanyakan orang teknologi informasi (TI) merupakan sinonim dari "Teknologi Baru", karena karena kaitannya yang erat dengan mesin microprosesor, seperti mikrokomputer, alat yang bekerja secara otomatis, seperti alat pengolah kata, dan lain sebagainya. Pengertian Teknologi Informasi (TI) berdasarkan British Advisory Council for Applied Research and Development (Dalam Zorkoczy, (1990: 12). adalah meliputi bidang ilmu pengetahuan, teknologi dan perekayasaan serta teknik pengelolaan yang digunakan dalam penanganan dan pengolahan informasi, penerapan bidang dan teknik tersebut, komputer dan interaksinya dengan manusia dan mesin, masalah sosial ekonomi serta budaya yang berkaitan. Memang banyak definisi tentang Teknologi Informasi, sehingga dalam "Macmillan Dictionary of Personal Computing and Communication" terdapat empat halaman yang menjelaskan tentang Teknologi Informasi (TI).

\subsection{Pre \& Pos Tes.}

Pre Test yaitu suatu bentuk pertanyaan, yang dilontarkan guru kepada muridnya sebelum memulai suatu pelajaran. Pertanyaan yang ditanya adalah materi yang akan diajar pada hari itu (materi baru). Pertanyaan itu biasanya dilakukan guru di awal pembukaan pelajaran. Pre test diberikan dengan maksud untuk mengetahui apakah ada diantara murid yang sudah mengetahui mengenai materi yang akan diajarkan. Pre test juga bisa di artikan sebagai kegiatan menguji tingkatan pengetahuan siswa terhadap materi yang akan disampaikan, kegiatan pre test dilakukan sebelum kegiatan pengajaran diberikan. Adapun manfaat dari diadakannya pree test adalah untuk mengetahui kemampuan awal siswa mengenai pelajaran yang disampaikan. Dengan mengetahui kemampuan awal siswa ini, guru akan dapat menentukan cara penyampaian pelajaran yang akan di tempuhnya nanti.

Post test merupakan bentuk pertanyaan yang diberikan setelah pelajaran/materi telah disampaikan. Singkatnya, post test adalah evalausi akhir saat materi yang di ajarkan pada hari itu telah diberikan yang mana seorang guru memberikan post test dengan maksud apakah murid sudah mengerti dan memahami mengenai materi yang baru saja diberikan pada hari itu. Manfaat dari 
diadakannya post test ini adalah untuk memperoleh gambaran tentang kemampuan yang dicapai setelah berakhirnya penyampaian pelajaran. Hasil post test ini dibandingkan dengan hasil pree test yang telah dilakukan sehingga akan diketahui seberapa jauh efek atau pengaruh dari pengajaran yang telah dilakukan, disamping sekaligus dapat diketahui bagian bagian mana dari bahan pengajaran yang masih belum dipahami oleh sebagian besar siswa.

\subsection{Penyelesaian Masalah.}

Sarana pembelajaran pada SMPN 8 Kota Pagar Alam dari kebanyakan Gurunya masih menggunakan sarana pendidikan konvensional sehingga sesuai semangat menyongsong era revolusi industry 4.0 SMPN 8 Kota Pagar alam yang serba sistem digital dirasa perlu untuk mengikuti perkembangan dan mempersiapkan perkembangan zaman, karena disadari betul kedepan sistem pendidikan semua berbasis sistem digital sehingga belajar dilakukan dengan sangat mudah dan dilakukan dimana saja, dan dengan bantuan sistem digital yang multimedia pembelajaran menjadi lebih mudah, maka dilakukan workshop multimedia pembelajaran bagi Guru SMPN 8 Kota Pagar Alam.

\section{PEMBAHASAN DAN HASIL.}

\subsection{Realisasi \& Pemecahan Masalah.}

Pelaksanaan pengabdian (PkM) diuraikan dalam tabel 1 dibawah ini, langkah-langkah ini menjadi acuan pengabdi sehingga pelaksanaan pengabdian berjalan sesuai rencana dan berjalan dengan baik, tidak melenceng dari ketentuan yang diatur oleh Lembaga Penelitian, dan Pengabdian Kepada Masyarakat, yakni sebagai berikut:

Tabel 1. Jenis Kegiatan

\begin{tabular}{|c|c|c|c|}
\hline Pelaksanaan & Waktu & Materi & Penyaji \\
\hline \multirow[b]{2}{*}{1 Hari } & $\begin{array}{l}08.00-09.00 \\
09.00-09.30\end{array}$ & $\begin{array}{l}\text { Pre Test } \\
\text { Persiapan dan pengenalan tentang teknologi } \\
\text { multimedia untuk pembelajaran. }\end{array}$ & \multirow{2}{*}{$\begin{array}{l}\text { Risnaini } \\
\text { Masdalipa } \\
\text { Debi } \\
\text { Gusmaliza }\end{array}$} \\
\hline & $\begin{array}{l}09.30-12.00 \\
12.00-12.30 \\
12.30-13.00\end{array}$ & $\begin{array}{l}\text { Panduan aplikasi multimedia dengan software } \\
\text { Ishoma } \\
\text { Post-test }\end{array}$ & \\
\hline
\end{tabular}

Maka berdasarkan tabel 1. Jenis atau rincian kegiatan diatas, pelaksanaan pengabdian menjadi terencana, terinci dengan baik sesuai urutan dan ketentuan yang telah disusun, maka jika dijelaskan lagi berikut penjelasannya:

Pengabdian yang dilakukan diawali dengan melakukan pre tes terhadap peserta workshop, pre tes dilakukan untuk memetakan pemahaman dari peserta terhadap teknologi pendidikan atau dalam hal ini multimedia pembelajaran, tes dilakukan terhadap seluruh peserta workshop agar menjadi gambaran bagi narasumber pada saat memberikan materi, menjadi materi yang benarbenar diperlukan oleh peserta workshop, berikutnya dilakukan pengenalan teknologi informasi dan teknologi pendidikan untuk multimedia pembelajaran tentu sesuai dengan kebutuhan yang didapat kesimpulannya dari pre tes sebelumnya, tips dan trik pembuatan dan penyusunan materi menjadi lebih menarik menggunakan tambahan multimedia, sehingga pelajaran yang disampaikan menjadi lebih menarik sehingga diyakini siswa tidak akan merasa bosan mendengarkan pemaparan materi yang dilakukan didepan kelas.

Berikutnya setelah teori, tips dan trik penyampaian materi dengan multimedia disampaikan dan peserta workshop memahami dengan baik terhadap materi dan tujuan, berikutnya disampaikan langsung praktek membuat multimedia pembelajaran menggunakan beberapa aplikasi pendukung yang dipahami oleh para peserta, langsung praktek dengan memasukan atau membuat materi yang mereka miliki menjadi materi yang interaktif dan mudah dicerna, mudah di pahami oleh peserta didik, terakhir dari workshop ini adalah diadakan tes lagi disebut dengan pos tes terhadap seluruh peserta, gunanya untuk mengetahui daya serap peserta terhadap materi yang disampaikan oleh narasumber, hasil dari tes ini menjadi masukan bagi pengabdi (nara sumber) juga menjadi masukan yang berguna bagi pihak LPPM STTP. 


\subsection{Pembahasan \& Hasil.}

Pengabdian telah selesai dilaksanakan dan berikut merupakan penjelasan hasil pengabdian yang dilakukan, yang pelaksanaannya berdasarkan rincian yang kegiatan yang telah dijelaskan pada pemaparan diatas, yang mana keberhasilan diukur oleh pengabdi sendiri berdasarkan pre dan pos tes yang dilakukan, berikut tabelnya:

Tabel 2. Pelaksanaan Kegiatan

\begin{tabular}{|l|l|}
\hline \multicolumn{1}{|c|}{ Materi } & \multicolumn{1}{c|}{ Hasil } \\
\hline Pendahuluan & $\begin{array}{l}\text { Pendahuluan pada worksop ini merupakan pre tes agar } \\
\text { peserta memahami maksud dari workshop sehingga peserta } \\
\text { fokus pada materi pelajaran yang diinginkan narasumber dan } \\
\text { sesuai dengan keperluan peserta sendiri. }\end{array}$ \\
\hline Pengenalan Teknologi Informasi & $\begin{array}{l}\text { Memahami perkembangan teknologi pendidikan, memahami } \\
\text { aplikasi yang mendukung \& dipergunakan untuk pendidikan } \\
\text { dan up to date. }\end{array}$ \\
\hline $\begin{array}{l}\text { Teknologi Multimedia } \\
\text { Pembelajaran }\end{array}$ & $\begin{array}{l}\text { Memahami dengan baik multimedia pembelajaran dan } \\
\text { memahami tips serta trik agar aplikasi multimedia yang } \\
\text { dibuat sesuai kebutuhan pelajar. }\end{array}$ \\
\hline Praktek membuat multimedia & $\begin{array}{l}\text { Peserta mampu mengaplikasikan ide kedalam multimedia } \\
\text { pembelajaran yang baik. }\end{array}$ \\
\hline Penutup & $\begin{array}{l}\text { Penutup dilakukan tes lagi untuk mengetahui keberhasilan } \\
\text { narasumber dalam menyampaikan materi workshop. }\end{array}$ \\
\hline
\end{tabular}

Tabel 2 menjelaskan keperhasilan pelaksanaan pengabdian kepada masyarakat yang dilakukan di SMPN 8 Kota Pagar Alam pertama dilakukan tes terhadap peserta workshop dari seluruh peserta yang jika dilihat usia sudah senior $100 \%$ belum terlalu memahami multimedia, dan ada peserta yang tidak sama sekali paham terhadap aplikasi komputer, sehingga bagi peserta yang demikian narasumber hanya melatih penggunaan aplikasi yang sangat umum seperti power point (PPT) saja, peserta dipersilahkan dengan bimbingan narasumber membuat materi dimasukan ke dalam power point yang ditambahani efek multimedia, seperti animasi, video maupun audio. Bagi peserta yang lain dibimbing berdasarkan aplikasi yang dikuasai dan beberapa aplikasi tambahan.

Berikutnya perkenalan aplikasi teknologi pendidikan, pada bagian ini banyak sekali pertanyaan terutama untuk penggunaan aplikasi baru, dan kemungkinan sistem pendidikan jarak jauh menggunakan sistem digital, seluruh peserta menjadi sadar perlunya skills tambahan pada bidang teknologi informasi, dan teknologi pendidikan. Teknologi multimedia pembelajaran peserta memahami tips menyisipkan video dan animasi pada teks materi yang disampaikan dan langsung dipraktekan sehingga workshop menjadi lebih menarik karena peserta menjadi penasaran dan merasa tertantang untuk menyelesaikan multimedia yang disusunnya.

Bagian akhir diketahui kemampuan peserta workshop meningkat dengan signifikan hal ini terlihat dari hasil pos tes yang dilakukan, semua perserta (100\%) merasa tertarik dengan teknologi informasi sehingga mereka menjadi lebih mudah menerima pemahaman baru dalam multimedia pembelajaran, terbukti mereka semua mampu menyelesaikan tugas yang diberikan narasumber dalam membuat menyiapkan sarana pembelajaran yang berbasis multimedia, bahkan mereka meminta perpanjangan waktu untuk lebih menguasai materi, sehingga bisa diidentifikasi berikut merupakan hasil akhirnya, yaitu:

a. Para peserta Guru Mata Pelajaran SMPN 8 Kota Pagar Alam mempunyai pemahaman dan pengetahuan yang baik tentang multimedia pembelajaran.

b. Seluruh peserta Guru SMPN 8 Kota Pagar Alam menjadi lebih paham fungsi Teknologi informasi yang aplikatif yang mendukung pembelajaran dalam kelas.

c. Pimpinan SMPN 8 Kota Pagar Alam terbantu dalam pemberian pemahaman terhadap teknologi informasi up to date yang aplikatif pada guru-guru senior yang basis keilmuannya tidak ada hubungan dengan teknologi informasi.

d. Menjadi nilai tambah di mata masyarakat terhadap kualitas pembelajaran di SMPN 8 . 
e. Efek dari sarana pembelajaran yang baik dan lengkap tentu membuat siswa/siswi SMPN 8 lebih mudah dalam menerima dan memahami pelajaran yang disampaikan guru.

f. Para Guru menjadi menjadi lebih merasa percaya diri saat mengajar didalam kelas.

\section{KESIMPULAN}

Kegiatan pengabdian yang dilakukan di SMPN 8 Kota Pagar Alam ini bertujuan melatih dan menambah pemahaman para guru yang sudah terbiasa mengajar, untuk beralih dan memanfaatkan teknologi multimedia pada saat mengajar didalam kelas, sehingga berdasarkan pelaksanaan pengabdian diperoleh beberapa kesimpulan berikut:

a. Workshop yang aplikatif langsung praktek dengan sedikit saja teori ternyata mampu meningkatkan semangat peserta untuk lebih giat belajar.

b. Menambah softskills atau kemampuan baru guru pada bidang multimedia pembelajaran.

c. Meningkatkan rasa percaya diri dengan kemampuannya ketika mengajar dalam kelas.

d. Membantu pimpinan SMPN 8 dalam memahamkan guru pada hal yang inovatif.

\section{SARAN}

Berdasarkan kejadian dan pengalaman yang ditemukan penulis pada saat pengabdian maka penulis dapat menyampaikan beberapa masukan atau sarana yang mungkin dapat menjadi bahan pemikiran semua orang, penyelenggaran, pelaksana atau pun tempat pengabdian, adapun sarana tersebut adalah sebagai berikut:
a. Pelaksanaan pengabdian disarankan dosen (pengabdi) diberikan keleluasaan waktu.
b. Pelaksanaan tidak harus berbarengan dengan KKN Mahasiswa.
c. Tempat pengabdian atau instansi pengabdian diperluas atau pengabdi dapat menentukan sendiri tempat pelaksanaan pengabdian.
d. Pemberian pasilitas dan pendanaan yang jelas terhadap kegiatan karena pengabdian adalah wajib dan tercantum dalam Tri Dharma.

\section{UCAPAN TERIMA KASIH}

Terima kasih disampaikan kepada semua pihak yang mendukung terlaksananya kegiatan pengabdian ini: LPPM, para dosen yang membantu, SMPN 8 dan Dinas Pendidikan Kota Pagar Alam.

\section{DAFTAR PUSTAKA}

[1] Hutchinson E. Sarah and Sawyer C. Stacey, 2000, Computers, Communications \& Information, McGraw Hill Companies Inc.

[2] Muslim, B. 2018. Pelatihan aplikasi editing video dengan filmora., Laporan Pengabdian Kepada Masyarakat, LPPM STT Pagaralam.

[3] Muslim, B. 2018. Pelatihan Pembuatan Blog Bagi Guru Ma Ponpes Darul Mutaqin Kota Pagaralam. NGABDIMAS. Vol 1. No.1. Bulan Juni, Hal. 6-11

[4] B. Muslim, Pengantar teknologi informasi. Yogyakarta: Deepublish, 2017.

[5] Muslim, B. (2018). Analisis system informasi (SI) terintegrasi di Perguruan Tinggi (PT) (Studi Kasus: STT Pagaralam). Jurnal Teknologi Informasi MURA, Vol 10. Page 83-91.

[6] Muslim, B (2014). Analisis rencana aplikasi teknologi informasi pada STT Pagar Alam. Proseding semnastik dan Magma. Issue: Aplikasi Teknologi dan sistem Informasi. PPP UBD Pres. Pages 397-404.

[7] Indonesia Services Education HP Tim, 2001, Manajemen Sistem Belajar Di Dunia Maya, Majalah Info Komputer.

[8] M.H Jogiyanto, 1995, Pengenalan Komputer, Andi Offset Yogyakarta.

[9] Horsley, M., Knight, B., \& Huntly, H. 2010. The role of textbooks and other teaching and 
learning resources in higher education in Australia: Change and continuity in supporting learning. IARTEM 1-Journal. 3(2). 43-61.

[10] Sadiman, A.S., Rahardjo, R., Haryono, A., \& Rahardjito. 2006. Media pendidikan: Pengertian, pengembangan, dan pemanfaatan. Jakarta: Rajagrafindo Persada.

[11] Menristekdikti. 2016. Panduan Pelaksanaan Penelitian dan Pengabdian Masyarakat di Perguruan Tinggi Edisi X Tahun 2016. hlm. 4

[12] Isro'Mukti, Y. (2017). Sistem Informasi Madrasah Aliyah Negeri Pagar Alam Berbasis Web. Indonesian Journal of Computer Science, 6(2), 192-205.

[13] Mukti, Y. (2017). Perencanaan Strategis Sistem Informasi Dan Teknologi Informasi Pada Sekolah Menengah Kejuruan Negeri 2 Pagar Alam. JURNAL ILMIAH BETRIK: Besemah Teknologi Informasi dan Komputer, 8(02), 83-92.

[14] Arif, A., \& Mukti, Y. (2017). Rancang Bangun Website Sekolah Menengah Pertama (SMP) Negeri 8 Kota Pagar Alam. JURNAL ILMIAH BETRIK: Besemah Teknologi Informasi dan Komputer, 8(03), 156-165.

[15] Isro'Mukti, Y. (2018, October). Sistem Informasi Manajemen Aset Sekolah Tinggi Teknologi Pagaralam Berbasis Web. In Seminar Nasional Teknologi Informasi dan Komunikasi (SEMNASTIK) (Vol. 1, No. 1, pp. 632-638).

[16] Mukti, Y. (2018). Rancang Bangun Website Sekolah Dengan Metode User Centered Design (UCD). JURNAL ILMIAH BETRIK: Besemah Teknologi Informasi dan Komputer, 9(02), 84-95.

[17] Mukti, Y. (2018). Pelatihan Maintance Komputer SMAN Pagar Gunung. NGABDIMAS, $1(1), 47-51$.

[18] Mukti, Y. I. (2019). Implementasi Jaringan Hotspot Kampus Menggunakan Router Mikrotik. Indonesian Journal of Computer Science, 8(2), 130-138.

[19] Mukti, Y. I., \& Puspita, D. (2019). Sistem Informasi Peringatan Dini Bencana Pada Kota Pagar Alam Berbasis Mobile. Jusikom: Jurnal Sistem Komputer Musirawas, 4(2), 65-74.

[20] Mukti, Y. I. (2019). SISTEM INFORMASI MONITORING KESEHATAN MASYARAKAT BERBASIS WEB MENGGUNAKAN METODE UNIFED MODELLING LANGUAGE. Jusikom: Jurnal Sistem Komputer Musirawas, 4(1), 1-8.

[21] Mukti, Y. I., \& Puspita, D. (2019, December). Web Based Disaster Early Warning System on Pagar Alam City. In Conference SENATIK STT Adisutjipto Yogyakarta (Vol. 5, pp. 309-316).

[22] Isro'Mukti, Y., \& Puspita, D. WEB BASED DISASTER EARLY WARNING SYSTEM ON PAGAR ALAM CITY.

[23] Puspita, D., \& Isro'Mukti, Y. (2019, December). Web-Based Culture Information System of Literature Besemah City of Pagar Alam. In Conference SENATIK STT Adisutjipto Yogyakarta (Vol. 5, pp. 303-308). 